\title{
Pacific States Census Division
}

National Cancer Institute

\section{Source}

National Cancer Institute. Pacific States Census Division. NCI Thesaurus. Code C76346.

A census division of the United States consisting of Alaska, California, Hawaii, Oregon, and Washington. 